\title{
Prolotherapy Injections for Diastasis Recti: A Case Report
}

\author{
Megan N. Strauchman, Mark W. Morningstar \\ Natural Wellness \& Pain Relief Center, Grand Blanc, MI, USA \\ Email: drmorningstar@nwprc.com
}

How to cite this paper: Strauchman, M.N. and Morningstar, M.W. (2016) Prolotherapy Injections for Diastasis Recti: A Case Report. Case Reports in Clinical Medicine, 5, 342-346.

http://dx.doi.org/10.4236/crcm.2016.59052

Received: September 1, 2016

Accepted: September 26, 2016

Published: September 29, 2016

Copyright $\odot 2016$ by authors and Scientific Research Publishing Inc. This work is licensed under the Creative Commons Attribution International License (CC BY 4.0).

http://creativecommons.org/licenses/by/4.0/

\begin{abstract}
This case report detailed the history and treatment of a female postpartum patient with diastasis recti. Treatment for this patient included the use of prolotherapy, an injection-based therapy using dextrose as the active compound. The solution used during the course of therapy was composed of $6 \mathrm{~mL}$ of $50 \%$ dextrose, $3 \mathrm{~mL}$ of $1 \%$ lidocaine, and $1 \mathrm{~mL}$ of methylcobalamin $(1000 \mathrm{mcg} / \mathrm{mL})$. Injections were administered every 2 weeks for a total of 7 prolotherapy sessions. Following the series of prolotherapy injections, there was a marked closure observed in the diastasis, decreasing from $2.7 \mathrm{~cm}$ to $0.5 \mathrm{~cm}$. The patient did not report any side effects, and no complications were observed or recorded. This appears to be the first case report documenting an improvement in abdominal diastasis recti following a course of prolotherapy. Within the limitations of the study design, further research is recommended to evaluate prolotherapy for diastasis recti in postpartum patients.
\end{abstract}

\section{Keywords}

Injections, Rectus Abdominus, Prolotherapy, Hernia

\section{Introduction}

Prolotherapy is a complementary and alternative medical therapy that has been used for over 100 years [1]. It is commonly used for chronic musculoskeletal pain conditions [2], such as knee osteoarthritis [1], chrondromalacia patella [3], coccygodynia [4], chronic low back pain [5], lateral epicondylitis [6], Achilles' tendinosis [7], and plantar fasciitis [8]. It is thought to work by introducing an irritant solution into injured tissue to stimulate the release of tissue growth factors [1]. It may also serve as a central pain modulator [1]. Different types of solutions may be selected by physicians' performing prolotherapy. The more common of these include dextrose [9], morrhuate sodium [10], and phenol-glycerine-glucose (P2G) [11]. 
Diastasis recti is a term used to describe a separation of the left and right sides of the abdominal wall of at least 2.7 centimeters [12]. It is a common result of childbearing caused by the repetitive stretching of the abdominal wall, which can result in midline or paraumbilical hernia [13]. Although it tends to be self-limiting postpartum, surgical intervention is often used for cosmetic purposes, as well as for hernia repair [14]. Exercise options are rare, but have been reported [15]. Even in cases where the diastasis recti improves, but doesn't resolve, after 6 months post-partum, the abdominal muscle strength does not return to normal [16]. Our case report details the management plan of a patient diagnosed with diastasis recti treated with prolotherapy. This report appears to be the first to document the use of prolotherapy to treat this common disorder. Written informed consent was obtained from this patient to use her non-identifying information.

\section{Case Report}

\subsection{Patient History and Exam}

A 25-year-old female Caucasian patient presented to a private integrative medicine office with a history of abdominal diastasis recti. This developed following the birth of her second child 8 months prior to initial presentation. Patient had 2 pregnancies, both of which were full term, vaginal deliveries. The second of her two children weighed 9 lbs, $5 \mathrm{oz}$ at birth, while the first weighed $8 \mathrm{lbs}, 2 \mathrm{oz}$. At the time of initial presentation, the patient was 5' 3 ' tall, and $120 \mathrm{lbs}$. She had a past medical history of diastasis recti, alopecia, irritable bowel syndrome, Hashimoto's thyroiditis, and headaches during menstruation. Laboratory testing demonstrated positive serum levels of IgM $(21 \mathrm{U} / \mathrm{ml})$ and $\mathrm{IgA}(23 \mathrm{U} / \mathrm{ml})$ candida antibodies, thyroglobulin antibodies $(1.5 \mathrm{IU} / \mathrm{mL}), 25(\mathrm{OH})$ vitamin D3 level of $25 \mathrm{ng} / \mathrm{mL}$, as well as decreased urinary levels of dehydroepiandros terone (DHEA) (14.3 nmol/dL), low testosterone, low estrone $(3.2 \mathrm{mcg} / \mathrm{g} \mathrm{Cr}$ ), and low estradiol ( $1.3 \mathrm{mcg} / \mathrm{g} \mathrm{Cr})$.

Upon inspection of the patient's abdomen, a separation of the abdominal wall was apparent just superior to the umbilicus, measuring $2.9 \mathrm{~mm}$. The patient was told by another provider that this separation would self-resolve approximately 6 months postpartum, but 8 months later it was still evident. The patient's desire was to correct this non-surgically. Figure 1 shows an illustration of this patient's diastasis recti.

\subsection{Treatment}

After she was informed of the potential benefits, risks, and complications associated with prolotherapy, the patient affirmed her intent to proceed with the procedure. A total of 4 injections were administered on the first treatment around the palpable site of supra umbilical muscle division. Solution was comprised of a combination of $6 \mathrm{~mL}$ of $50 \%$ dextrose, $3 \mathrm{~mL}$ of $1 \%$ lidocaine, and $1 \mathrm{~mL}$ of methylcobalamin $(1000 \mathrm{mcg} / \mathrm{mL})$. Prolotherapy injections were administered every two weeks for a total of 7 prolotherapy sessions.

During the first 5 sessions, a total of 4 injections were used to administer the dextrose 
solution. For the final two prolotherapy sessions this decreased to 2 injections. The patient did not report and complications or side effects throughout the duration of treatment, and tolerated the injections well. Figure 2 shows prolotherapy injection points for this patient.

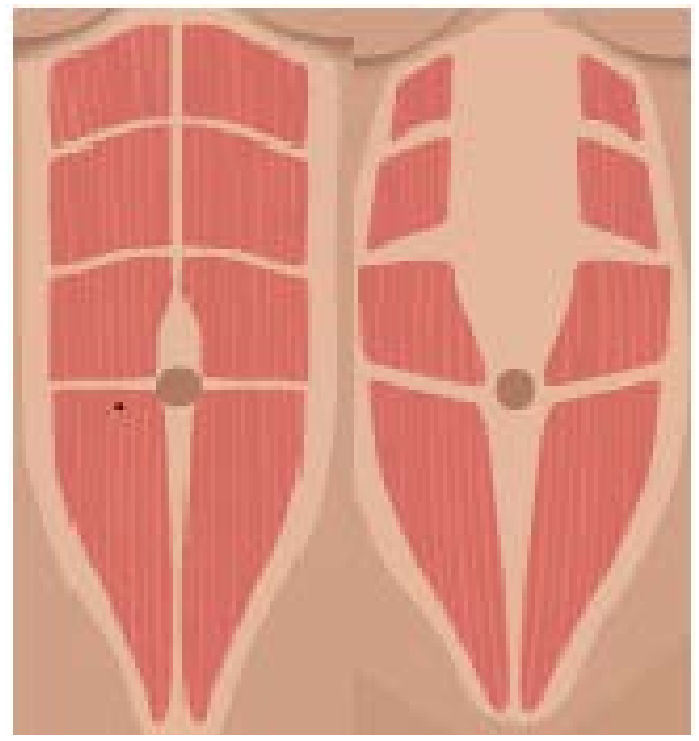

Figure 1. Normal rectus abdominus (left); Diastasis recti (right). Ilustration reprinted with permission from beyondfitmom.com

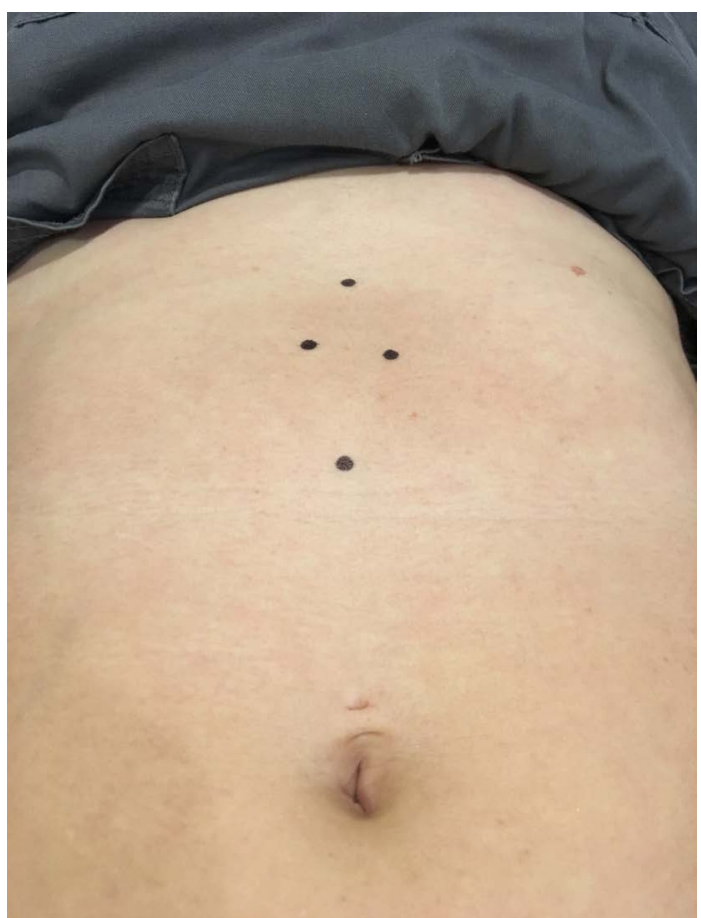

Figure 2. Prolotherapy injections points used in this caset. 


\subsection{Outcome}

Patient was re-evaluated at 14 weeks following the first prolotherapy session. Good approximation of the rectus abdominus was observed, with palpable closure measuring $0.5 \mathrm{~cm}$, a decrease from the initial $2.9 \mathrm{~cm}$.

\section{Discussion}

Although prolotherapy has been consistently used for chronic pain syndromes, due to its postulated mechanism of action, prolotherapy may be a novel way to treat diastasis recti when it is not self-limiting. This may be preferable to surgical options to repair any subsequent hernias or negative cosmetic impact.

It is important to also discuss the safety profile of prolotherapy. In a survey of approximately 500,000 patients treated for a variety of health conditions. They included 29 reports of a pneumothorax, 24 accounts allergic reactions, and 12 cases of hospitalization for an undisclosed reason [17]. Common side effects can include injection site redness and localized tenderness for 5 - 7 days post-injection [1]. This track record makes prolotherapy a desirable intervention when compared to more invasive alternatives.

Over the course of the treatment presented in this case report, the patient was also prescribed various nutraceuticals based upon her symptoms and laboratory findings, including DHEA $5 \mathrm{mg}$ b.i.d., pregnenolone 50mg daily, and cholecalciferol 10,000 $\mathrm{mg}$ daily. While it is possible that these nutraceutical interventions may have helped to play a part in the observed improvement in her diastasis recti, this has never been previously reported to do so in the literature.

Because this is a case report, there are limitations associated with this study design. First, a lack of a control limits our ability to generalize or make assumptions on broader patient populations. Second, the apparent reduction in abdominal wall separation following prolotherapy could possibly be, however unlikely given the length of time this patient had the diagnosis, attributed to self-resolution over time as many of these cases do. Future studies on this topic could include testing multiple types of injection solutions to determine which work the best, as well as to compare against control patients to determine effectiveness compared to natural history.

\section{Conclusion}

In this case report, the treatment and the outcome of a patient with abdominal diastasis recti who received a therapeutic trial of dextrose prolotherapy were reported. Following this therapeutic trial, the patient's abdominal separation closed from $2.9 \mathrm{~cm}$ to $0.5 \mathrm{~cm}$. The patient will be followed to assess long-term benefits.

\section{References}

[1] Rabago, D., Slattengren, A. and Zgierska, A. (2010) Prolotherapy in Primary Care Practice. Primary Care: Clinics in Office Practice, 37, 65-80. http://dx.doi.org/10.1016/j.pop.2009.09.013 
[2] Fleming, S., Rabago, D.P., Mundt, M.P., et al. (2007) CAM Therapies among Primary Care Patients Using Opioid Therapy for Chronic Pain. BMC Complementary and Alternative Medicine, 7, 15. http://dx.doi.org/10.1186/1472-6882-7-15

[3] Hauser, R.A. and Sprague, I.S. (2014) Outcomes of Prolotherapy in Chondromalacia Patella Patients: Improvements in Pain Level and Function. Clinical Medicine Insights: Arthritis and Musculoskeletal Disorders, 7, 13-20.

[4] Khan, S.A., Kumar, A., Varshney, M.K., Trikha, V. and Yadav, C.S. (2008) Dextrose Prolotherapy for Recalcitrant Coccygodynia. Journal of Orthopaedic Surgery, 16, 27-29.

[5] Yelland, M., Glasziou, P., Bogduk, N., Schluter, P. and McKernon, M. (2004) Prolotherapy injections, Saline Injections, and Exercises for Chronic Low Back Pain: A Randomized Trial. Spine, 29, 9-16. http://dx.doi.org/10.1097/01.BRS.0000105529.07222.5B

[6] Johnson, G.W., Cadwallader, K., Scheffel, S.B. and Epperly, T.D. (2007) Treatment of Lateral Epicondylitis. American Family Physician, 76, 843-848.

[7] Yelland, M.J., Sweeting, K.R., Lyftogt, J.A., Ng, S.K., Scuffham, P.A. and Evans, K.A. (2011) Prolotherapy Injections and Eccentric Loading Exercises for Painful Achilles tendinosis. A Randomised Trial. British Journal of Sports Medicine, 45, 421-428. http://dx.doi.org/10.1136/bjsm.2009.057968

[8] Ryan, M.B., Wong, A.D., Gillies, J.H., Wong, J. and Taunton, J.E. (2009) Sonographically Guided Intratendinous Injections of Hyperosmolar Dextrose/Lidocaine: A Pilot Study for the Treatment of Chronic Plantar Fasciitis. British Journal of Sports Medicine, 43, 303-306. http://dx.doi.org/10.1136/bjsm.2008.050021

[9] Hackett, G.S., Hemwall, G.A. and Montgomery, G.A. (1993) Ligament and Tendon Relaxation Treated by Prolotherapy. 5th Edition, Gustav A. Hemwall, Oak Park.

[10] Scarpone, M., Rabago, D.P., Zgierska, A., Arbogast, G. and Snell, E. (2008) The Efficacy of Prolotherapy for Lateral Epicondylosis: A Pilot Study. Clinical Journal of Sport Medicine, 18, 248-254. http://dx.doi.org/10.1097/JSM.0b013e318170fc87

[11] Banks, A. (1991) A Rationale for Prolotherapy. Journal of Orthopaedic Medicine, 13, 54-59.

[12] Benjamin, D.R., Van de Water, A.T.M. and Peiris, C.L. (2014) Effects of Exercise on Diastasis of the Rectus Abdominis Muscle in the Antenatal and Postnatal Periods: A Systematic Review. Physiotherapy, 100, 1-8. http://dx.doi.org/10.1016/j.physio.2013.08.005

[13] Nahas, F.X., Augusto, S.M. and Ghelfond, C. (1997) Should Diastasis Recti Be Corrected? Aesthetic Plastic Surgery, 21, 285-289. http://dx.doi.org/10.1007/s002669900127

[14] Siddiky, A.H. and Kapadia, C.R. (2010) Laparoscopic Plication of the Lineaalba as a Repair for Diastasis Recti-A Mesh Free Approach. Journal of Surgical Case Reports, 5, 3.

[15] Chiarello, C.M., Falzone, L.A., McCaslin, K.E., Patel, M.N. and Ulery, K.R. (2005) The Effects of an Exercise Program on Diastasis Recti Abdominis in Pregnant Women. Journal of Women's Health Physical Therapy, 29, 11-16. http://dx.doi.org/10.1097/01274882-200529010-00003

[16] Liaw, L.J., Hsu, M.J., Liao, C.F., Liu, M.F. and Hsu, A.T. (2011) The Relationships between Inter-Recti Distance Measured by Ultrasound Imaging and Abdominal Muscle Function in Postpartum Women: A 6-Month Follow-Up Study. Journal of Orthopaedic \& Sports Physical Therapy, 41, 435-443. http://dx.doi.org/10.2519/jospt.2011.3507

[17] Dorman, T. (1993) Prolotherapy: A Survey. Journal of Orthopaedic Medicine, 15, 49-50. http://dx.doi.org/10.1080/1355297x.1993.11719720 
Submit or recommend next manuscript to SCIRP and we will provide best service for you:

Accepting pre-submission inquiries through Email, Facebook, LinkedIn, Twitter, etc. A wide selection of journals (inclusive of 9 subjects, more than 200 journals)

Providing 24-hour high-quality service

User-friendly online submission system

Fair and swift peer-review system

Efficient typesetting and proofreading procedure

Display of the result of downloads and visits, as well as the number of cited articles

Maximum dissemination of your research work

Submit your manuscript at: http://papersubmission.scirp.org/

Or contact crcm@scirp.org 